\title{
UNiVERSAL AND ReLATIVE RATIONALITY
}

\author{
NATHANIEL GoldBerG \\ Washington and Lee University
}

\begin{abstract}
In this paper I illustrate how a basic kind of universal rationality can be profitably combined with undeniable instances of relativism. I do so by engaging Michael Friedman's recent response to a challenge from Thomas Kuhn.
\end{abstract}

Keywords: Communicative rationality, Michael Friedman, Thomas Kuhn, relativism, scientific revolutions.

In this paper I illustrate how a basic kind of universal rationality can be profitably combined with undeniable instances of relativism. I do so by engaging Michael Friedman's recent response to a challenge from Thomas Kuhn. The challenge is this. Suppose that Kuhn's historiography of science is correct: the history of science is demarcated into periods of normal science punctuated by revolutions calling into doubt standards of evaluation. How can this historiography be reconciled with the possibility of universal rationality, so that researchers in one normal-scientific tradition can transition rationally to another? While Kuhn initially was taken to have maintained that no reconciliation is attainable, he later responded to the challenge by trying to reconcile his historiography with the possibility of just such rationality. That response, however, has not always been regarded sympathetically.

In §1 I explain Friedman's rejection of Kuhn's response and then Friedman's own response to the challenge of reconciling a Kuhnian historiography of science with the possibility of universal rationality. In §2 I evaluate Friedman's response. In §3 I introduce my distinction between communicative form and content. In §4 I rely on that distinction to respond to Kuhn's challenge myself. I then go beyond Kuhn and Friedman to show that universalism and relativism can both figure in an overarching account of rationality. In $\S 5$ I apply this to Friedman's historical example.

\section{Kuhn and Friedman}

To understand Friedman's rejection of Kuhn's response to the challenge of reconciliation, and Friedman's own response to that challenge, consider Kuhn's views that Friedman targets. Initially (1962) Kuhn maintains that periods of normal science are governed by paradigms, such things as shared examples, problems, solutions, Principia 13(1): 67-84 (2009).

Published by NEL - Epistemology and Logic Research Group, Federal University of Santa Catarina (UFSC), Brazil. 
methods, worldviews, and standards around which scientific communities coalesce, and against which beliefs and actions of their members can be rationally assessed. ${ }^{1}$ Kuhn later speaks not of 'paradigms' but of 'disciplinary matrices' and 'exemplars' (1979, essay 12; 1996), and finally of 'lexical taxonomies' (or 'lexica') (2002, essays $1-4,11)$. Such lexica are networks of kind terms embodying empirical concepts constraining the articulation and development of research. Here I follow Friedman and use 'paradigm' to name the semantic components of Kuhn's 'paradigm' and 'matrix', and his 'lexicon'. 2

Kuhn also maintains throughout that periods of normal science are interrupted by revolutions, during which a community surrenders its paradigm and considers replacements. Once a replacement is chosen, a new period of normal science commences. Nonetheless, Kuhn explains, successive paradigms are incommensurable, in virtue of which revolutions mark discontinuities in thought. Originally (1962, chs. 9-13) for Kuhn two paradigms are incommensurable if there is no common measure or framework against which to compare their observations or values, or the meanings of their terms. ${ }^{3}$ Absent such a framework, beliefs in favor of one paradigm rather than another cannot be rational. Rationality therefore remains relative to periods of normal science.

Kuhn responds to his own challenge of reconciling the possibility of universal rationality with his historiographic picture by distinguishing forms of incommensurability and qualifying each. Kuhn (2002, essay 2$)$ ceases talking about observational incommensurability. He $(1979,321-2 ; 1996,185,199,206)$ also mollifies claims about value incommensurability by insisting that accuracy, simplicity, fruitfulness, consistency, and efficiency provide a universal framework against which scientists can compare competing paradigms. Finally, meaning incommensurability, according to which there is no language into which terms from competing paradigms are translatable without residue, is said to arise "[o]nly for a small subgroup of (usually interdefined) terms" $(2002,36)$. The following picture emerges. Paradigm-transcendent values provide a universal framework against which scientists can evaluate competing paradigms via their translatable parts. A scientist is rational in choosing one paradigm over another if claims entailed by that paradigm better satisfy these values than do claims entailed by the other $(2002,113,119,251)$. The possibility of universal rationality is thereby meant to be secured.

Friedman finds Kuhn's response to the challenge deficient in several ways and against them fashions his own response. Consider two alleged deficiencies. First, Friedman (2001, 52) maintains, even if accuracy and the like do provide a common framework of values, meaning incommensurability prevents the framework's application in any neutral way. Now Friedman is silent on why the ability fairly to compare most claims made from the perspective of two paradigms is insufficient to allow rational transitions between them. Yet suppose Kuhn is right: incommensura-

Principia 13(1): 67-84 (2009). 
bility between the Newtonian and Einsteinian paradigms- to use a favored example $(2002,44)$-is localized to terms like 'force' and 'mass'. If Newtonians and Einsteinians cannot fairly compare claims about mass and force, then few significant claims can be so compared. ${ }^{4}$ While local incommensurability may not always be problematic for Kuhn, I am concerned with times when it is.

Second, Friedman maintains, "[p]ointing to the obvious (if not entirely unproblematic) fact that science has nonetheless continued to increase its quantitative accuracy, precision, and so on [still] appears to be a quite inadequate response to the full force of this relativistic challenge" $(2001,53)$, for doing so fails to distinguish two kinds of rationality. Appropriating Jürgen Habermas' (1984) terms, Friedman calls them 'instrumental' and 'communicative rationality'. For Friedman paradigm choice based on values like accuracy can be only instrumentally rational. Paradigm adoption becomes a means to the end of maximizing accuracy and the like in empirical research. ${ }^{5}$ Nonetheless any scientist choosing a paradigm for such reasons fails to treat it as something that can and should be understood and deliberated over in its own right. The difference is between adopting a paradigm merely as a tool with no regard for how or why it works, and embracing one based on a full understanding of its principles and presuppositions. Friedman explains that a Newtonian and Einsteinian would both agree that general relativity yields more accurate predictions for the advance of the perihelion of Mercury $(2001,85)$. However, relying on values only like accuracy, the Newtonian "can at most accept the new theory [or paradigm] as a 'black box' predictive device ... [T] he theory is not even a possible object of communicative rationality - a possible candidate for mutual rational understanding and deliberation" $(2001,95)$. The paradigm becomes a calculating device whose inner workings proponents of competing paradigms can neither comprehend nor discuss. The black box remains closed. It is because theories implicated in those paradigms would remain intelligible only to their proponents that Friedman concludes that the "full force of the relativist challenge" remains.

Conversely for Friedman communicative rationality would be achieved in a revolution should scientists choose a paradigm by discussing it directly. Competing paradigms become objects of "mutual rational understanding and deliberation" (Friedman 2001, 95) rather than mere tools for calculation. While instrumental rationality renders prospective paradigms black boxes, communicative rationality, by allowing scientists to discuss and understand paradigms in their own right, opens those boxes. In fact, according to Friedman, communicative rationality is inherent in normal science. A paradigm itself provides the means for understanding and deliberating over issues relative to a normal-scientific tradition. It also establishes a framework against which beliefs and actions of scientists can be rationally assessed. But that is normal science, and Kuhn's challenge concerns revolutionary science. Thus though Kuhn and Friedman both want revolutionary science to have a framework

Principia 13(1): 67-84 (2009). 
against which paradigm adoption can be rational, Kuhn thinks that values like accuracy establish an appropriate framework for rational evaluation. Friedman, however, insists that only the possibility of establishing communicative rationality responds to the full force of Kuhn's challenge.

Friedman's first move in securing communicative rationality is distinguishing scientific paradigms, which govern normal science, from meta-paradigms, which he urges govern revolutionary science. For Friedman a scientific paradigm, as a framework constitutive of a scientific tradition, defines a space of empirical possibilities by delineating what kinds of objects can exist. Because this would constrain the articulation and development of research, Friedman's understanding of a paradigm is consistent with my own. Thus the Newtonian paradigm establishes that physical objects possess mass, exist in absolute space, and obey specific laws of motion. Further, claims that scientists make can be rationally assessed against that framework. Anyone who from the perspective of the Newtonian paradigm incorrectly calculates the force of gravity acting on an object is in error, and anyone who refuses to correct his error is from that perspective irrational.

Conversely for Friedman a meta-paradigm would be a framework constitutive of a philosophical debate. The kind of debate that Friedman considers are learned disagreements concerning the more conceptual or metaphysical assumptions implicit in scientific theories. Examples include the debate between Helmholtz and Poincaré surrounding the foundations of geometry (Friedman 2001, 67) and the debate concerning absolute versus relative motion of objects in space to which Descartes, Leibniz, Euler, and Mach contributed (107). For Friedman such debates define a space of conceptual possibilities, detailing what counts as intelligible, and so what speculative moves scientists are justified in entertaining when stepping outside normal science. If a certain philosophical position is seen by scientists as intelligible and so can be discussed, then these scientists might regard the position as grounds for taking seriously a scientific paradigm that assumes it. Because the meta-paradigm provides a framework capable of establishing understanding and deliberation, moves in a particular revolution can be assessed as communicatively rational if sanctioned by it. ${ }^{6}$

Thus Friedman argues that Einstein appealed to the debate concerning absolute versus relative motion to allow his light principle, according to which the velocity of light in a vacuum is constant, and principle of equivalence, according to which bodies in a uniform gravitational field and uniformly accelerated frame of reference behave identically, to be taken seriously as foundations for a new paradigm in science. Einstein thereby provided the Newtonian philosophical or "meta-paradigmatic" reasons to find his scientific paradigm intelligible. The Newtonian could then join those who already adopted the Einsteinian paradigm to see whether it was explanatory of the physical world. Nonetheless, Friedman explains, finding paradigms intelligible does

Principia 13(1): 67-84 (2009). 
not make them translatable. This is fortunate. Friedman's project is to reconcile Kuhn's historiography of science with the possibility of universal rationality. According to this historiography, the history of science is punctuated by the adoption of untranslatable paradigms. Any response to Kuhn's challenge must leave competing paradigms partially untranslatable.

Later I modify Friedman's idea to incorporate into my own, so the details of his example need not concern us now. Instead we must consider one further step of Friedman's response to Kuhn's challenge. So far Friedman has conceded that scientific knowledge is relative to particular scientific paradigms, observed that philosophical knowledge is relative to particular philosophical debates, and then argued that appealing to philosophical debates (qua meta-paradigms) allows transitions from one scientific paradigm to another to be rational. But then so far rationality itself remains relative.

Friedman attempts to recover universal communicative rationality in two steps. First, he $(2001,60,101)$ follows Kuhn in maintaining that proponents of one scientific paradigm can rationally reconstruct previous paradigms in terms of their own. The relativistic physicist can redescribe the paradigm of classical mechanics as a limiting case of relativity theory, suitable for calculating properties of objects at low velocities. Past science can therefore be understood as employing the same principles and constraints, and so framework for mutual rational evaluation, as the current paradigm does. This, Friedman explains, provides a sense of retrospective universal rationality: current and past paradigms alike can be seen as amenable to the same canons of rational assessment. Second, Friedman (64-5) appeals to Kant's own idea of a focus imaginarius to provide a sense of prospective universal rationality. Kant identifies the focus imaginarius as a regulative principle that guides science without constitutively constraining it, encouraging progress toward the goal of systematic unity. ${ }^{7}$ Friedman brings Kant's regulative ideal to the constitutive domain by encouraging scientists to imagine that our present scientific paradigm itself represents one stage of a converging process. Our framework for mutual rational evaluation would then be seen as closing in on the final such framework. We are therefore entitled to regard prospective rationality as universal also: current and future paradigms can be seen as amenable to the same canons of rational assessment too.

Friedman takes all this to reconcile Kuhn's historiography of science with the possibility of universal communicative rationality.

\section{Evaluating Friedman's Response}

Though, unlike Friedman, I continue to see a role for values like accuracy in responding to Kuhn's challenge, I agree that the rationality worth attaining in revolutionary

Principia 13(1): 67-84 (2009). 
science is universal and communicative. Before exploring my own response to that challenge, here I offer a comment on and criticism of Friedman's.

The comment is that Friedman references two different first/meta-level distinctions worth differentiating. Friedman uses the first distinction, the only one considered above, to differentiate scientific paradigms as first-level from philosophical debates qua meta-paradigms as meta-level. According to him, the Newtonian paradigm establishes that physical objects exist in absolute Euclidean space. The philosophical debate concerning geometry encourages scientists to find it intelligible for objects to exist in space that is not Euclidean, while the debate concerning motion encourages them to find it intelligible for physical objects to exist in space that is not absolute. Hence Friedman's initial first/meta-level distinction concerns different things about objects. The former details what about them is empirically possible; the latter details what about them we can find conceptually possible.

The second first/meta-level distinction that Friedman references is Kant's. Friedman writes: "Whereas each of the first-level sciences, whether empirical," like physics, "or a priori," like geometry, "has its own characteristic objects, philosophy, as a second-level or meta-level discipline, has no such objects of its own" (2001, 8, my emphasis). Rather for Kant philosophy as meta-level concerns conditions on the possibility of cognition about objects. While Friedman's distinction is between what is empirical and intelligible about objects, Kant's is between objects and conditions on the possibility of cognition about them. It is between objects and what is required to represent objects cognitively.

While Friedman discusses both first/meta-level distinctions, they markedly differ. Further, I have separated them to use the latter in my own response to Kuhn's challenge. But first I must lodge the following criticism of Friedman. He urges that contemporary scientists project their own paradigm's principles and constraints onto past and future paradigms alike, and that the resulting retrospective and prospective rationality is universal. That rationality is not, however, universal in any unqualified sense. The Einsteinian who assesses the Newtonian's claims as retrospectively rational because she reconstructs the Newtonian paradigm in terms of her own, relativizes what counts as rational to her paradigm. The Einsteinian who anticipates that future physicists' claims will be prospectively rational because she imagines future paradigms in terms of her own, relativizes what counts as rational to her paradigm also. Whatever rationality emerges on Friedman's view therefore remains relative. Worse, unless past or future scientists can be counted as rational by contemporary lights, on Friedman's view they cannot be counted as rational at all. Rather than solving the problem of relativism, Friedman worsens the relativism by transforming it into chauvinism.

Nor does it matter that the focus imaginarius is a regulative principle. Not only does Friedman invoke it only in the prospective case, urging actual retrospective

Principia 13(1): 67-84 (2009). 
reconstruction. Even prospectively he uses it in a constitutive manner, requiring scientists to foresee the construction of future paradigms in terms of their present one. In both cases what counts as rational remains relative to the current paradigm. Neither does Friedman think that the fixity of the focus imaginarius across revolutions grounds universal rationality; only its application does. That application, however, as we have seen, results in rationality that is chauvinistic. Finally, while the focus imaginarius does force a kind of systematic unity onto the history of science, on Friedman's view systematic unity is by itself insufficient to ground university rationality. Only systematic unity relative to the current paradigm is. Nonetheless for Friedman because each current paradigm becomes universally rational, at each stage in the history of science past and future science becomes rational relative to something else. Friedman's claim to have established a "truly universal human rationality" (2001, 48, my emphasis) loses force once we realize that the measure of this rationality is always fleeting. ${ }^{8}$

Ultimately I suggest a way to avoid this problem. Doing so requires first introducing my distinction between communicative form and content.

\section{Communicative Form and Content}

Recall that for Friedman a lexical taxonomy-what Friedman and I both call a 'paradigm'-is a network of kind terms embodying empirical concepts constraining the articulation and development of research. A paradigm is therefore linguistic. Further, even if Friedman is right that philosophical debates can be useful during scientific revolutions, their primary function is to constrain the articulation and development of philosophical research. They do so by providing acceptable vocabulary for discussion. A debate is therefore linguistic also. Unlike scientific vocabulary embodied in a lexicon, philosophical vocabulary embodied in a debate need not consist of kind terms, though it might contain some. It does, however, establish general connections among objects. Thus the debate concerning absolute versus relative motion offers vocabulary for understanding objects as spatial. That debate might introduce terms like 'coexistence', 'inertial reference frame', and 'initial' versus 'uniform velocity'. By describing objects with these terms participants in the philosophical debate can discuss spatial properties that objects might intelligibly be said to possess.

Once we recognize with Kuhn that paradigms provide vocabularies, and extend the suggestion to Friedman that debates provide vocabularies too, we can see that a scientific paradigm provides communicative content for a community of scientists. A philosophical debate in turn provides communicative content for a community of philosophers-and, if Friedman is right, for scientists during revolutions. By 'communicative content' I mean signs and symbols that, once interpreted, become vo-

Principia 13(1): 67-84 (2009). 
cabulary constraining the articulation and development of research in whatever discipline is under discussion. Communicative content provides the possible subject matter for discourse, once interpreted the words used to frame-and in so doing circumscribe-conversation. 'Force' and 'coexistence', once interpreted, provide just such subject matter, and so just such communicative content, for their respective discursive realms. This idea of communicative content is consistent with Friedman's idea of a scientific paradigm defining a space of empirical possibilities, since communicative content, when interpreted by scientists, establishes categories for empirical research by delineating what kinds of objects can exist. It is also consistent with Friedman's idea of a philosophical debate defining a space of conceptual possibilities, since communicative content, when interpreted by philosophers or scientists, establishes categories for philosophical research-including during revolutionary science-by delineating what we can find intelligible about objects. Thus Friedman is still correct that paradigms and debates stand toward one another in his (but not Kant's) first/meta-level manner. He just failed to realize that from the perspective of communication these paradigms and debates both provide communicative content. From that perspective, their first/meta-level standing is obscured.

Once we assume this communicative perspective, we also recognize that communicative content is by itself insufficient for communication. As I have already suggested, that content must be interpreted. Neither 'force' nor 'coexistence' can be meaningful to someone who does not know how to interpret it as meaningful. Words do not wear their meaning on their sleeve. Communicative content is communicable only if interpretive rules have been applied to it. Call whatever rules interpret communicative content 'communicative form'. Communicative form is what permits communicative content to constrain the articulation and development of research in the first place. Uninterpreted communicative content remains lines on a page or vibrations in the air. Communicative form puts communicative content-scientific, philosophical, otherwise-into a form that is communicable. It allows shapes and sounds to have meaning.

We can further understand the communicative form/content distinction by appealing to the two first/meta-level distinctions that, as we saw in §2, Friedman himself discusses. Kuhn's paradigms and Friedman's debates exemplify Friedman's first/meta-level distinction. That distinction is between what is empirically possible about objects, on the one hand, and what we can find conceptually possible about them, on the other. Communicative content and communicative form, conversely, exemplify a variant on Kant's first/meta-level distinction. Kant's distinction is between objects, on the one hand, and conditions on the possibility of cognition about them, on the other. From the perspective of communication, Kuhn's paradigms and Friedman's debates each concern objects, albeit linguistic ones, like 'force' and 'coexistence'. Nonetheless rather than concerning conditions on the possibility of cog-

Principia 13(1): 67-84 (2009). 
nition about these objects, communicative form, as rules for interpretation, concern conditions on the possibility of communication about them. Communicative form allows 'force' and 'coexistence' to be objects of communication insofar as scientists can engage one another in conversation by employing them. Via interpretive rules, utterances can be interpreted. Scientists, philosophers, and language users generally can then take one another's utterances to be meaningful and via those utterances converse.

Thus interpretive rules generally function as conditions on the possibility of communication much as, for Kant, epistemic rules like the categories function as conditions on the possibility of cognition. ${ }^{9}$ Further, communicative form alone is insufficient for communication. Absent communicative content, interpretive rules lay fallow and communication is impossible. Likewise, communicative content alone is insufficient also. Absent communicative form, whatever content is offered remains uninterpreted utterances, raw material from which communication could emerge. In Kantian spirit we can then note that communicative form without content is empty, while communicative content without form is mute.

I can make the communicative form/content distinction clearer still by mentioning a view that best exemplifies it. Donald Davidson's (2001, essay 9) account of interpretation, informed by his later work on triangulation (2002, essays 6-9, 13-4), maintains that an interpreter can interpret a speaker's utterances, or communicative content, by constructing a Tarski-style truth theory for the speaker's language (see Goldberg 2004b, c; 2008; 2009b). Theory construction is in turn guided by two interpretive rules: interpret systematically by applying Alfred Tarski's (1944) recursive method, properly modified for natural languages, to the language being interpreted; and interpret charitably by whenever possible finding the speaker's utterances self-consistent and responsive to circumstances in her environment. ${ }^{10}$ As I understand it, in Davidson's account the interpreter applies communicative form, or interpretive rules, to the speaker's utterances, or communicative content. Communication is itself then possible. Further, because from a communicative perspective Kuhn's paradigms and Friedman's debates are first-level in a Kantian sense, concerned with objects, while Davidson's interpretive account is meta-level, concerned with conditions on the possibility of communication about these objects, we might call Davidson's account a 'communicative meta-paradigm'.

Now I happen to think that Davidson's account comes closest to embodying the rules that we actually (though usually only implicitly) use during communication. His "communicative meta-paradigm" roughly approximates the one that we in fact employ. ${ }^{11}$ So let us treat Davidson's meta-paradigm as a source of interpretive rules or communicative form, and Kuhn's paradigms and Friedman's debates as sources of vocabulary or communicative content. Next I offer a three-part outline of how doing so provides a way to attain universal communicative rationality, that truly universal

Principia 13(1): 67-84 (2009). 
human rationality which Friedman sought in vain, without surrendering the genuine sense in which claims and actions remain relative to a paradigm. To make vivid how my response to Kuhn's challenge overcomes problems plaguing Friedman's, I illustrate it with Friedman's own account of the transition from classical to relativistic physics.

\section{Universal and Relative Rationality}

\subsection{Part One: communicating about overlapping content}

Friedman is right that practitioners of competing scientific paradigms cannot always regard one another's paradigm as an object of mutual rational understanding and deliberation. Though some vocabulary peripheral to the Newtonian's and Einsteinian's paradigms would be intertranslatable without loss, what each means by 'force' and 'mass' would not be. The Newtonian and Einsteinian, applying interpretive rules to this communicative content, would then be unable fully to intertranslate between paradigms. Once interpreted, some of their words would mean incompatible things. The scientists would fail to share significantly overlapping communicative content.

Part One of my response to Kuhn's challenge requires that the scientists find significant content elsewhere to share. Two scientific paradigms $A$ and $B$-as sources of communicative content-can fail to overlap significantly with one another while succeeding in doing so with some $C$. Friedman requires that this third source of content, this $C$, be a philosophical debate. On my view it could be such a debate or another scientific paradigm, description of practical applications of paradigms, perspective on shared instrumentation, or something else. Since not all communicative content would overlap with two competing paradigms in an appropriate manner, the options are limited. Nonetheless they need not be as limited as Friedman would have them. More importantly, unlike Friedman, I recognize that this $C$ is just a further source of communicative content. From a communicative perspective the scientists must apply the formal constraints of a communicative meta-paradigm to let the scientists communicate about $C$. From that perspective $A, B$, and $C$ are all first-level; the communicative meta-paradigm is meta-level.

Now suppose that proponents of competing scientific paradigms $A$ and $B$ do find some $C$. Since $C$ would significantly overlap with both paradigms, the joint overlap could provide reasons to regard the other's paradigm, $A$ or $B$, as worth considering, while $A$ and $B$ would themselves remain partially untranslatable. Though Friedman misconstrues its lessons, his example clarifies my idea. The Newtonian and Einsteinian might, as Friedman suggests, appeal to the philosophical debate surrounding the foundations of geometry. Nonetheless while that debate does open a space of conceptual possibilities, any move from the Newtonian to the Einsteinian paradigm is better seen as horizontal, passing through a set of shared communicative content

Principia 13(1): 67-84 (2009). 
that bridges the two, rather than (a la Friedman) as some vertical appeal to a debate qua meta-paradigm. Terms like 'parallel' and 'constant' versus 'variable curvature', part of the philosophical debate proper, would be interpretable and so understandable by the Newtonian and Einsteinian alike. Yet only the latter might think that spatial curvature should be termed 'variable', and what the former and latter each mean by 'parallel' would differ. By applying a communicative meta-paradigm and so interpreting and communicating about the philosophical debate, the Newtonian could thus be reminded of terms as he employs them and transition to employing terms as the relativistic physicist herself does. Because the philosophical debate would consist of all these terms, it could provide a semantic bridge from classical mechanics to relativity theory. Because the bridge would consist of vocabulary from a debate concerning geometry rather than from either Newtonian or Einsteinian physics proper, their respective paradigms would remain partially untranslatable into one another.

Moreover, through interpreting and in turn communicating with the Einsteinian -made possible by applying communicative form to overlapping content-the Newtonian could come to realize where on issues in the foundations of geometry he and his counterpart differ. He could then have reasons to see how these issues inform the relativistic paradigm itself. The Newtonian, immersed in the philosophical debate, might want to know how an apparently heterodox definition of 'parallel' informs discussions about the propagation of light. Because this desire would come from discussing the philosophical debate, the Newtonian would have communicative reasons from the debate to transition to the relativistic paradigm. He could then tentatively adopt the paradigm's (partially incommensurable) worldview, making sense of the space of empirical possibilities that it establishes. The paradigm would no longer appear to the Newtonian as a black box. And this could be so even though the classical and relativistic paradigms would remain partially untranslatable, a desideratum on any response to Kuhn's challenge.

Finally, though there is no guarantee that practitioners of scientific paradigms $A$ and $B$ will find some shared $C$, none is needed. All that is needed is a first step toward reconciling Kuhn's historiography with the possibility of trans-revolutionary (universal and communicative) rationality, and that depends on the mere possibility of finding some $C$ that when a communicative meta-paradigm is applied to it would overlap significantly with $A$ and $B$ without making $A$ and $B$ fully intertranslatable. Friedman's own example, construed in my way rather than his, exemplifies just this possibility.

\subsection{Part Two: applying Kuhn's values in a communicative context}

Suppose that via transitional vocabulary and a communicative meta-paradigm one scientist can have communicative reasons to start discerning the space of empirical

Principia 13(1): 67-84 (2009). 
possibilities that the other's paradigm delineates. The scientist can then work her way into the other's partially incommensurable worldview. Here the Newtonian can take the relativistic paradigm to be an object of mutual rational understanding and deliberation. The Newtonian is then in a position to garner reasons from the paradigm itself to adopt it. But what kind of reasons would these be?

While Friedman is right that a competitor paradigm should not be treated as a "black box' predictive device" (2001, 95), he is wrong to downplay its importance as a predictive device altogether. Though Friedman does not explicitly exclude values like accuracy from the process of paradigm adoption, he makes no room for them either. Perhaps that is because Friedman fails to recognize that scientists can understand and deliberate over a paradigm in terms of these values, which can themselves be brought into the communicative fold. Rather than treating the paradigm as a means to the end of maximizing accuracy and the like in empirical research, scientists can treat these values themselves as means to the end of further understanding and evaluating the paradigm.

In fact discussing the paradigm in terms of values like these is crucial to establishing the possibility of trans-revolutionary rationality itself. Paul Hoyningen-Huene (1992) is right that for a paradigm's adoption to be rational, it must satisfy values deemed important by the scientific community, to the extent deemed important, and in the manner deemed important. The Newtonian would be irrational to adopt the Einsteinian paradigm if its claims were less accurate across the board. Some framework of values must be in place for paradigm adoption to be capable of rational assessment. What needs to be added to Hoyningen-Huene's account, however, is a way of understanding how a competitor paradigm can be treated as an object of communicative rationality. My proposal of transitional vocabulary plus a communicative meta-paradigm does this. If a paradigm is so treated, then scientists can understand and deliberate not only over whether, to what extent, and in what way the new paradigm satisfies those values. They can also understand and deliberate over which values are important, how they should be weighted, and how they should be construed in the first place. Further, by discussing which theoretical elements are responsible for the fulfillment of which values and so which mechanisms yield which results, scientists can understand and deliberate over how and why the paradigm satisfies these values at all. What needs to be added to a framework of values, therefore, is a framework for communication. A communicative meta-paradigm like Davidson's promises to offer that.

Finally, even if scientists start with differing lists, weightings, or construals of values, they can talk through these differences to reach consensus on how the new paradigm should be judged. Part One of my proposal mollifies the effects of meaning incommensurability by appealing to transitional vocabulary and a communicative meta-paradigm. Part Two now explains how once the effects of meaning incommen-

Principia 13(1): 67-84 (2009). 
surability are mollified, proponents of different paradigms can overcome instances of value incommensurability. Even if such proponents initially prefer to evaluate paradigms via different, differently weighted, or differently construed values, their ability to communicate about these differences would let them reach enough consensus to evaluate the paradigms in a mutually accepted way. They can discuss, debate, and adjudicate values like accuracy and decide together how to proceed with them. There can be communicatively rational reasons to change commitments to values.

\subsection{Part Three: wedding relativism to universalism}

By themselves Parts One and Two of my response to Kuhn's challenge leave communicative rationality relative to each community of scientists. The Newtonian paradigm establishes one framework for rational assessment; the Einsteinian, another; and the philosophical debates concerning geometry and motion, to which the Newtonian and Einsteinian might both appeal, other frameworks still. Though I have argued that members of different communities can via appealing to a communicative meta-paradigm reach consensus on values, that consensus is relative to those scientists who are communicating. How can we ground universal communicative rationality and then wed such rationality to these undeniable instances of relativism?

To ground universal rationality, we must find a framework for rational assessment that, unlike Friedman's, does not relativize rationality to one source of communicative content among others. To ground the universal rationality as communicative, we must find a framework that, unlike Kuhn's, is not comprised of values like accuracy but that enables communication about overlapping content, against such values, instead. Davidson's interpretive account, construed as a communicative meta-paradigm, does both.

Qua communicative meta-paradigm, Davidson's account grounds universal communicative rationality insofar as it functions as a communicative meta-paradigm or framework for rational evaluation at the most basic level. As I explained in Part One, anyone constraining her research by the Newtonian or Einsteinian paradigm should be construed as communicatively rational relative to that paradigm. Likewise anyone constraining her research by the philosophical debate concerning geometry or motion should be construed as communicatively rational relative to that debate. By explaining how rationality relative to various discourses still exists, I avoid Friedman's chauvinism. Further, as I explained in Part Two, values differ, are weighted differently, and are construed differently in different communities. Though I explained how scientists can communicate about these issues, the resulting communicative rationality remains relative to whatever consensus on values they reach. Nonetheless these scientific and philosophical researchers can also be assessed as

Principia 13(1): 67-84 (2009). 
communicatively rational at a more basic, universal level insofar as their utterances are interpreted by anyone at all. Davidson is correct: "Successful interpretation necessarily invests the person interpreted with basic rationality" $(2002,211)$. Basic rationality is at the base of, and so shared by, anyone interpreted by anyone else; it is universal in that sense. Whenever interpretation is successful, some interpreter has successfully applied interpretive rules to the speaker. She has shown that the speaker's utterances are systematic, self-consistent, and responsive to the environment. And any speaker whose utterances are shown to have these features can herself be deemed rational in the most basic sort of way. This is so regardless of whether what she says is rational relative to one paradigm and not another, and whether the values that she deems important have been deemed important within or without her community. 12

Thus the Newtonian and Einsteinian can each have beliefs and perform actions that are communicatively rational relative to her own paradigm. Insofar as they participate in the philosophical debate concerning geometry or motion, each can have beliefs and perform actions that are communicatively rational relative to a shared debate. Further, through discussion the Newtonian and Einsteinian can together reach consensus on values, so their beliefs and actions can be communicatively rational relative to that consensus then too. Nonetheless the Newtonian and Einsteinian can also be assessed as having beliefs and performing actions that are communicatively rational in a universal way, as long as their utterances are interpreted. At the level of paradigms, debates, and values, each one's beliefs and actions could be communicatively rational in a relative way. At the level of interpretive rules used to interpret these paradigms and debates and discuss these values, each one's beliefs and actions could be communicatively rational in a universal way. ${ }^{13}$ The key to wedding rational relativism and universalism is recognizing that each operates at a different level. Communicative content and values lets us be relativists, while communicative form-in the form of a communicative meta-paradigm-lets us be universalists, in our theory of rationality.

Now just how universal would that rationality be? Suppose that what I have identified as Davidson's meta-paradigm does approximate the correct account of how communication is possible. Though scientific paradigms and values change over time, the meta-paradigm would remain the same. While ancient Greek theories of movement toward natural resting places have given way to contemporary theories of quantum gravity-each of which informed and was perhaps informed by discussions in philosophy-the most basic constraints on interpreting ancient Greek and contemporary physicists and philosophers, and language users generally, have remained constant. Then and now interpretation would require following two rules: be systematic and be charitable. Then and now were these rules successfully applied to a speaker's utterances, the speaker could be regarded as rational in

Principia 13(1): 67-84 (2009). 
the most basic sense. Further, on Davidson's view these interpretive rules extend into the past and future: "[n]othing more is possible, and nothing more is needed" $(2001,197)$ for interpretation than the account that he provides. Changing scientific paradigms, definitive of scientific revolutions and relative rationality, can therefore occur within a context of a fixed communicative meta-paradigm, definitive of universal rationality. ${ }^{14}$

\section{Example}

Reconsider Friedman's example in full. Friedman is right that the Newtonian cannot qua Newtonian treat the Einsteinian paradigm as an object of mutual rational understanding and deliberation. He is also right that the Einsteinian can appeal to the philosophical debates concerning geometry and motion to make her paradigm intelligible to the Newtonian. Friedman's understanding of those philosophical debates as meta-level proves unhelpful, however. We are better off understanding the debates as providing overlapping communicative content. Coupled with a communicative meta-paradigm, content from the debates can be communicated. The Newtonian still cannot fully compare his paradigm to the relativistic paradigm. But he can communicate with the Einsteinian about those debates, potentially providing reasons to consider how the Einsteinian incorporates philosophical issues from the debates into the relativistic paradigm itself. $\mathrm{He}$ can then have reasons to assume the Einsteinian perspective.

Should the Newtonian assume it, then he could start discerning the space of empirical possibilities that this new paradigm delineates. This would allow him no longer to treat that paradigm as a black box. Further, having had reasons from philosophy to consider the competitor paradigm, the Newtonian might now have reasons from that paradigm itself, when considered against Kuhn's values, to adopt it. That could happen if the scientist discusses with members of the community which values are important (e.g., accuracy and simplicity), how they should be weighted (accuracy over simplicity), how they should be interpreted (accuracy regarding prediction versus simplicity regarding explanation), and the extent to which the relativistic paradigm satisfies them (exceptional on accuracy, mediocre on simplicity). Thus Einstein's accurate prediction of the advance of the perihelion of Mercury could provide reason for physicists already familiar with the relativistic paradigm to adopt the paradigm for themselves. Though the Newtonian and Einsteinian paradigms remain partially untranslatable into one another, the transition from one to the other could nonetheless be rational.

Finally, in virtue of fixed forms of communication applied to successively overlapping content, paradigm adoption could be rational in a universal and communica-

Principia 13(1): 67-84 (2009). 
tive way. Simultaneously, in virtue of varying communicative content and values, the same adoption could be rational in a relative way too. We have therefore responded to Kuhn's challenge-and in so doing combined universalism and relativism into a single account of rationality. ${ }^{15}$

\section{References}

Bird, A. 2002. Thomas Kuhn. Princeton, NJ: Princeton University Press.

Chen, X. 1997. Thomas Kuhn's Latest Notion of Incommensurability. Journal for General Philosophy of Science 28: 257-73.

Davidson, D. 1990. The Structure and Content of Truth. Journal of Philosophy 87: 279-328.

2001 [1984]. Inquiries into Truth and Interpretation. New York: Oxford University Press.

- 2002. Subjective, Intersubjective, Objective. New York: Oxford University Press. 2004. Problems of Rationality. New York: Oxford University Press.

-. 2005. Truth, Language, and History. New York: Oxford University Press.

Friedman, M. 2001. Dynamics of Reason. Stanford, CA: Center for the Study of Language and Information.

Goldberg, N. 2004a. Do Principles of Reason Have "Objective but Indeterminate Validity"? Kant-Studien 95: 405-25.

- 2004b. E Pluribus Unum: Arguments against Conceptual Schemes and Empirical Content. The Southern Journal of Philosophy 42: 411-38.

- 2004c. The Principle of Charity. Dialogue 43: 671-83.

- 2008. Tension within Triangulation. The Southern Journal of Philosophy 46: 367-83. 2009. Triangulation, Untranslatability, and Reconciliation. Philosophia 37: 261-80.

-. (forthcoming). Historicism, Entrenchment, and Conventionalism. Journal for General Philosophy.

Goldberg, N. \& M. Rellihan. 2008. Incommensurability, Relativism, Scepticism: Reflections on Acquiring a Concept. Ratio 21: 147-67.

Habermas, J. 1984. The Theory of Communicative Action. Boston: Beacon Press.

Hoyningen-Huene, P. 1992. The Interrelations between the Philosophy, History, and Sociology of Science in Thomas Kuhn's Theory of Scientific Development. British Journal for the Philosophy of Science 42: 487-501.

1993. Reconstructing Scientific Revolutions: Thomas S. Kuhn's Philosophy of Science. Trans. A. T. Levine. Chicago: University of Chicago Press.

Kant, I. 1998 [1787]. Critique of Pure Reason. 2d edition. Trans. P. Guyer and A. W. Wood. New York: Cambridge University Press.

Kuhn, T. S. 1962. The Structure of Scientific Revolutions, 1st edition, without postscript. Chicago: University of Chicago Press.

—_ 1979. The Essential Tension. Chicago: University of Chicago Press.

- 1996 [1970]. Postscript. In The Structure of Scientific Revolutions. 2d edition. Chicago: University of Chicago Press, 174-210.

. 1999. Remarks on Incommensurability and Translation. In Favretti, R. R.; Sandri, G.; Scazzieri, R. (eds.) Incommensurability and Translation: Kuhnian Perspectives on Scientific Communication and Theory Change.. Northampton, MA: Edward Elgar Pub., Inc., 33-8.

Principia 13(1): 67-84 (2009). 
2002. The Road Since Structure. Ed. J. Conant and J. Haugeland. Chicago: University of Chicago Press.

Laudan, L. 1990. Normative Naturalism. Philosophy of Science 57: 44-59.

1996. Beyond Positivism and Relativism. Boulder, CO: Westview Press.

Lepore, E. and K. Ludwig. 2007. Donald Davidson: Meaning, Truth, Language, and Reality. New York: Oxford University Press.

Masterman, M. 1970. The Nature of a Paradigm. In Criticism and the Growth of Knowledge, ed. I. Lakatos and A. Musgrave. New York: Cambridge University Press, 59-89.

Richardson, A. W. 2002. Narrating the History of Reason Itself: Friedman, Kuhn, and a Constitutive A Priori for the Twenty-First Century. Perspectives on Science 10: 253-74.

Tarski, A. 1944. The Semantic Conception of Truth and the Foundations of Semantics. Philosophy and Phenomenological Research 4: 341-75.

NATHANIEL GOLDBERG

Department of Philosophy

Washington and Lee University

Lexington, VA 24450

United States

GoldbergN@wlu. edu

Resumo. Neste artigo ilustro como um tipo básico de racionalidade universal pode ser combinado de maneira lucrativa com instâncias inegáveis de relativismo. Isso é feito analisando a recente resposta de Michael Friedman a um desafio feito por Thomas Kuhn.

Palavras-chave: Racionalidade comunicativa, Michael Friedman, Thomas Kuhn, relativismo, revoluções científicas.

\section{Notes}

${ }^{1}$ Masterman (1970) lists 21 different meanings of Kuhn's 'paradigm'.

2 For more on Kuhn's paradigms, matrices and exemplars, and lexica, see Bird (2002, ch. 3) and Hoyningen-Huene (1993, ch.4).

${ }^{3}$ For discussion of different types of incommensurability in Kuhn's writings, see HoyningenHuene (1993, ch.6). For discussion of why incommensurability is unavoidable whether one adopts Kuhn's view or not, see Goldberg and Rellihan (2008).

${ }^{4}$ See Goldberg and Rellihan (2008), and Chen $(1997,261)$.

5 Though it is unclear how Friedman's instrumental rationality differs from Laudan's (1990, 1996), only Laudan thinks that all good reasons are instrumental.

${ }^{6}$ Richardson is right that by allowing revolutions to be mediated by meta-paradigms Friedman wants "kinder, gentler revolutions" (2002, 263) than Kuhn (1962, ch.12) wanted. Further, though Friedman does argue that from a historical perspective principles of past paradigms can be seen as evolving into those of present paradigms by a "series of natural transformations" $(2001,66)$, he insists that mediation by a meta-paradigm remains essential for the transition to be rational. Otherwise paradigms can be judged merely instrumentally from the perspective of the scientists involved and from a properly historical perspective also, no matter how natural the transformations might be.

Principia 13(1): 67-84 (2009). 
${ }^{7}$ Kant (1998) introduces the focus imaginarius at A644/B672. For discussion of Kant's related principles of reason, see Goldberg (2004a)

${ }^{8}$ Nor can Friedman appeal to his claim that the principles of one paradigm can be seen as evolving naturally from those of another. (See note 6). For Friedman two paradigms become objects of communicative rationality only after a meta-paradigm is invoked. Whatever communicative rationality can be secured would remain relative to the particular meta-paradigm mediating the change at each stage.

${ }^{9}$ Kuhn's later writings (2002, essays 1-5), and especially Hoyningen-Huene's (1993, 7881) reconstruction of them, are suggestive of rules for learning vocabulary. Such rules are different from those for interpreting vocabulary. Moreover, Kuhn's account concerns only kind terms. Rules for interpretation must explain how to interpret other terms and whole sentences.

${ }^{10}$ For discussion of radical interpretation, see Lepore and Ludwig 2007, part II. For discussion of the principle of charity, see Goldberg $2004 \mathrm{c}$.

11 Though, as I (Goldberg 2004b, c; 2008) have noted, Davidson's account has problems, I think that they are ultimately surmountable. But can that account be wed to Kuhn's? Davidson (2001, essay 13) treats Kuhn's (1962) paradigms as conceptual schemes, only to argue that there can be no schemes. He does so by contending that if schemes are anything they are untranslatable languages, and then urging that his interpretive account establishes that all languages are necessarily intertranslatable. How can Davidson's account be a metaparadigm, let alone permit partially untranslatable paradigms?

First, Davidson identifies his account as a "scheme" $(1990,282)$ applicable to interpreting utterances. My only disagreement is to identify it as a meta-paradigm applicable to the same. Davidson himself therefore has the resources with which to distinguish communicative form, consisting of interpretive rules, from communicative content, consisting of utterances to which these rules would be applied. Second, I have demonstrated elsewhere (Goldberg 2004b, c; Goldberg and Rellihan 2008) that Davidson's account does not entail that all languages are necessarily intertranslatable. And third, Kuhn (1999, 34-5) notes that even if as Davidson contends the Newtonian could interpret the Einstein's 'mass', there is no unequivocal way for the Newtonian to translate it into her own paradigm. The Newtonian would instead have to adopt the Einsteinian's 'mass' as separate vocabulary. But then partial untranslatability - between the natural part of the Newtonian's paradigm and this Einsteinian adoption-remains.

${ }^{12}$ Davidson would himself reject any such rational relativism along with the very idea of a conceptual scheme. Nonetheless see note 1.

${ }^{13}$ For Davidson's take on the connection between the interpretation of utterances and the rationality of beliefs and actions, see 2001 , essays $9,10,13$ and $1990 ; 2004$, essays 8,10 , respectively.

${ }^{14}$ For an attempt on purely Davidsonian terms to overcome untranslatability, see Goldberg 2009. For Friedman's attempt to establish a sense in which mathematical claims presupposed by scientific paradigms express necessary truths, see Goldberg (forthcoming).

${ }^{15}$ Thanks go to Alyssa Bernstein, Matthew Burstein, Mark LeBar, Chauncey Maher, James Mattingly, James Petrik, Matthew Rellihan, and Tad Zawidzki.

Principia 13(1): 67-84 (2009). 